\title{
Research on Fluorescence Spectroscopy Characteristics of Dissolved Organic Matter of Landfill Leachate in the Rear Part of Three Gorges Reservoir
}

\author{
Zhigang Xie and Wei Guan \\ College of Materials \& Chemical Engineering, Chongqing University of Arts and Sciences, Chongqing 402160, China \\ Correspondence should be addressed to Wei Guan; guanwei951030@126.com
}

Received 8 August 2014; Revised 7 September 2014; Accepted 8 September 2014

Academic Editor: Wen Zeng

Copyright @ 2015 Z. Xie and W. Guan. This is an open access article distributed under the Creative Commons Attribution License, which permits unrestricted use, distribution, and reproduction in any medium, provided the original work is properly cited.

Three-dimensional fluorescence and infrared spectroscopy analysis of the leachate dissolved organic matter (DOM) of the Three Gorges was reported in spring, summer, and autumn seasons, respectively. Studies show that, that organic matter of landfill leachate in Yongchuan, Dazu and Jiangjin is the class of fulvic-like acid and protein-like fluorescence. The study also found that the longer the time of the pile of garbage, the lower the content of class of protein-like concentration, and the higher the concentration of fulviclike acid, indicating that the protein waste material in the humification process is easy degradation. However, the same source of DOM is similar in the functional group composition and molecular structure. Characteristic frequency area analysis showed that humic acids (HA), and fulvic acids (FA) contain more than hydrophilic organic matter (HyI) aromatic ring structure, and FA aromatic ring structure is the most. Because of Chung-amide $\mathrm{NH}$ deformation vibration, there are strong absorption peaks in the $1562 \sim 1572 \mathrm{~cm}^{-1}$ for various components; HyI contains many organic nitrogen compounds and fatty acids.

\section{Introduction}

Chinese major cities' living garbage is given priority to kitchen waste, its organic matter composition is high, calorific value matter content is little, the moisture content is high, making landfill leachate water amount large, and water contained more organic pollutants $[1,2]$. DOM in landfill leachate comes from landfill organic matter biodegradation, which is similar to the degradation of organic matter in the soil. DOM refers to organic matter retained in water after filtering through the $0.45 \mathrm{um}$ film. Generally, in leachate DOM can be divided into three ingredients such as HA, FA, and HyI. HA and FA in waste leachate are known as humic substances (HS).

Ultraviolet-visible spectroscopy, infrared spectroscopy, fluorescence spectroscopy, nuclear magnetic resonance (NMR), pyrolysis + GC-MS, and other analysis technology are widely used in chemistry to determine structure and functional characteristics of organic matter [3-8]. Many researchers in other disciplines at home and abroad applied these for chemical structure characteristics analysis of hydrophilic organic matter, humic acid, and fulvic acids of natural water body or soil. At present, there are also some abroad researchers who carry out these techniques to study chemical structure and functional characteristics of dissolved organic matter in the landfill leachate [9-12]. In order to further understand the chemical properties of organic matter in leachate, the most prevalent method is ultravioletvisible spectroscopy and infrared spectroscopy. In domestic, the related research reports about this technology used in leachate organic matter are rare. However, three-dimensional fluorescence spectrum can be used to characterize the leachate DOM and organic fluorophores specific information can be obtained; infrared spectroscopy can be further used to characterize the structure characteristics of DOM rapidly.

The reports of three-dimensional fluorescence and infrared spectrum used to study the characteristics of waste leachate quality are very rare and those combined with two kinds of spectral technology in molecular level study landfill leachate are rarely reported. In order to understand physical and chemical characteristics and their seasonal variation of landfill leachate, three-dimensional fluorescence, infrared 
TABLE 1: Water quality parameters landfill leachate.

\begin{tabular}{lccccc}
\hline Season & Region & $\mathrm{pH}$ & $\mathrm{COD}$ & $\mathrm{UV}_{254}$ & E4/E6 \\
\hline \multirow{3}{*}{ Spring } & Yongchuan & 8.0 & 5162 & 123.9 & 1.857 \\
& Jiangjin & 8.2 & 5225 & 139.5 & 2.667 \\
& Dazu & 8.2 & 5045 & 74.2 & 1.310 \\
\hline \multirow{2}{*}{ Summer } & Yongchuan & 8.3 & 3918 & 66.4 & 2.784 \\
Autumn & Yongchuan & 7.9 & 2255 & 28.1 & 1.777 \\
& Jiangjin & 8.5 & 2332 & 29.2 & 2.680 \\
& Dazu & 8.3 & 3668 & 46.8 & 1.125 \\
\hline
\end{tabular}

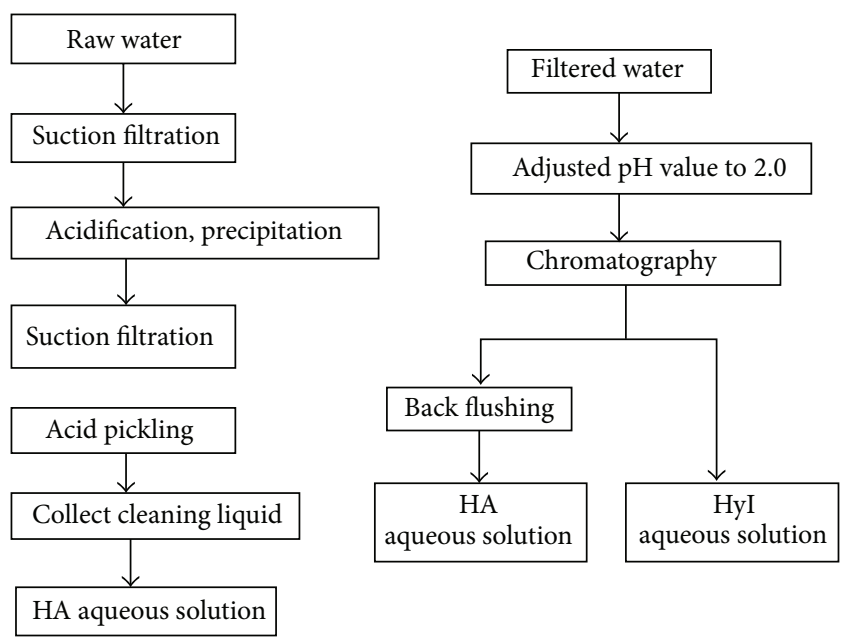

FIGURE 1: Separation procedures to fractionate DOM in leachate.

spectroscopy, UV-Vis spectra, and elemental are used to characterize rear parts of the Three Gorges for the leachate DOM. It has a positive guiding significance on developing landfill leachate treatment technology and on studying the landfill leachate influence on environment.

\section{Materials and Methods}

2.1. Sample Collection. Landfill leachate samples were collected from leachate equalization basin of domestic waste treatment plant in Yongchuan, Jiangjin, and Dazu. The landfill times were 4,5 , and 6 years in these three sites, respectively. When water samples is brought to the laboratory, it is immediately centrifuged under the condition of $12000 \mathrm{r} / \mathrm{min}$ for $10 \mathrm{~min}$, followed by supernatant filtration with $0.45 \mu \mathrm{m}$ microporous membrane, and the organic matter in filtrate is the DOM. The basic physical and chemical parameters of water samples are shown in Table 1.

2.2. Enrichment and Separation of the DOM. XAD-8 resins are adopted to enrich and to separate DOM in leachate, namely, HA, FA, and HyI. XAD-8 resins are widely used in the enrichment and separation of DOM in sewage and natural water [13-16]. Separation step is shown in Figure 1.

Water amount relationship is recorded before and after the enrichment and separation, and the water samples are stored separately at $4^{\circ} \mathrm{C}$ in refrigerator. Some water samples are taken out to freeze and to dry. Freeze drier, manufactured at Beijing Boyikang Experimental Instrument Co., Ltd., with working condition temperature less than $-50^{\circ} \mathrm{C}$ and pressure less than $20 \mathrm{~Pa}$, was used to analyze HA, FA, and HyI after freeze drying.

2.3. Three-Dimensional Fluorescence Spectrum Analysis. Fluorescence spectrum determined by HITACHI F-7000 fluorescence spectrophotometer. Instrument light source is $150 \mathrm{~W}$ xenon lamp, and photomultiplier tube voltage is $700 \mathrm{~V}$. Excitation and emission monochromator are diffraction grating, and excitation and emission slit width is $5 \mathrm{~nm}$. Excitation light wavelength range is $200 \sim 450 \mathrm{~nm}$, and emitting light wavelength range is $250 \sim 550 \mathrm{~nm}$. Data are processed with Sigmaplot software and are characterized by contour line diagram, with reference to ultrapure water as blank correction on basis of the Raman scattering of water.

2.4. Infrared Spectrum Analysis. Fourier transformation infrared spectroscopy (FTIR) was adapted in infrared spectrum analysis. 1 2 mg freeze dried HA, FA, HyI, and intact samples from landfill leachate are taken and are mixed with about $300 \mathrm{mg} \mathrm{KBr}$ (spectrum pure). These samples are ground to the fine particles and are blended to the particle size of smaller than $2 \mathrm{um}$. These are pressed to flakiness in $(5 \sim 10) \times 10^{7}$ pa for $1 \mathrm{~min}$. FTIR-8400 spectrometer scan is used in the range of $4000 \sim 1200 \mathrm{~cm}^{-1}$, and the spectrum is measured and recorded.

\section{Results and Analysis}

3.1. Three-Dimensional Fluorescence Spectrum of Leachate $D O M$. Different DOM has different fluorescent groups. Our previous research [17] suggests that the three-dimensional fluorescence characteristic of wastewater DOM is shown in Table 2. Fulvic-like fluorescence (Peak A and Peak C) is relevant with carbonyl and carboxyl of humus structure [1822]. However, protein-like fluorescence (Peak D, Peak B, Peak S, and Peak T) is relevant with amino acid structure [17, 23-26].

The position and intensity of fluorescence peak are different. Figure 2 is partial diagram of the three-dimensional fluorescence spectra of landfill leachate DOM. Table 3 shows the fluorescence and fluorescence intensity of percolate DOM.

According to Figure 2, for spring landfill leachate, the fluorescence peak type of Yongchuan includes fulvic-like acid (visible region, UV region, resp.), high excitation wavelength tryptophan-like, high excitation wavelength tyrosine-like, and humic acid. The fluorescence peak of low excitation wavelength tryptophan-like and low excitation wavelength tyrosine-like is weak. Leachate fluorescence peak type of Spring Jiangjin is visible fulvic-like acid, high excitation wavelength tryptophan-like, UV fulvic-like acid, high excitation wavelength tyrosine-like, and high excitation wavelength tryptophan-like, respectively. The leachate fluorescence peak type of Dazu and Jiangjin is similar. The UV fulvic-like acid fluorescence intensity of Dazu is stronger than that of Jiangjin, and the high excitation wavelength tryptophan-like 
TABLE 2: Major fluorescence peak for DOM.

\begin{tabular}{lcll}
\hline Peak & Ex/nm & Em/nm & Matter \\
\hline I & $350 \sim 440$ & $430 \sim 510$ & Humic-like \\
A & $240 \sim 270$ & $370 \sim 440$ & UV fulvic-like \\
C & $310 \sim 360$ & $370 \sim 450$ & Vis fulvic-like \\
D & $220 \sim 230$ & $280 \sim 310$ & Low-excitation wavelength tyrosine-like \\
B & $270 \sim 280$ & $280 \sim 310$ & High-excitation wavelength tyrosine-like \\
S & $220 \sim 230$ & $320 \sim 350$ & Low-excitation wavelength tryptophan-like \\
T & $270 \sim 280$ & $320 \sim 350$ & High-excitation wavelength tryptophan-like \\
\hline
\end{tabular}

fluorescence intensity of Dazu is weaker than that of Jiangjin. There is no humic-like fluorescence peak in percolate of Dazu and Jiangjin; maybe it is related to longer landfill time.

We test the dissolved organic matter of summer Yongchuan landfill leachate. The fluorescence peak type includes ultraviolet fulvic-like acid, visible fulvic-like acid, high excitation wavelength tyrosine-like, and high excitation wavelength tryptophan-like.

The fluorescence peak type of autumn landfill leachate includes UV fulvic-like acid, visible fulvic-like acid, high excitation wavelength tryptophan-like, and low excitation wavelength tryptophan-like. The strongest fluorescence peak is Yongchuan infiltration fluorescence intensity of filtrate is strong, and Dazu infiltration fluorescence intensity of filtrate is weak.

Leachate fulvic-like fluorescence (including visible and ultraviolet region) is related to the carbonyl and carboxyl groups in humus structure. Protein-like fluorescence is related to aromatic amino acid structure. The study of threedimensional fluorescence spectroscopy indicates that the dissolved organic matter of landfill leachate of Three Gorges Reservoir (Yongchuan, Jiangjin, and Dazu) mainly includes organics with aromatic amino acid structure and organics with carbonyl and carboxyl groups.

Fluorescent intensity of proteins in landfill leachate decreased with the increase of landfill time, while the trend of fulvic-like acid is opposite. This indicated that with the prolonged time of the landfill, microorganisms become more active, and degradation of organic matter is more obvious. With the increase of landfill time, there are obvious red shifts in fluorescence peak. This result indicated that, during the stacking process, except for the degradation of organic matter, microbial would break down proteins to produce small organic molecules. Thus, landfill proteins fluorescence intensity in the filtrate weakened, and fluorescence spectrum red shifted. The seasonal variations of leachate organic matter content are similar to the research of Coble [18], but the change magnitude is relatively small. However, the variation characteristics in spring and summer are inconsistent with Lou's study results [19]. Lou considered that summer leachate organic matter content should be reduced due to the dilution effect of rainfall. Yongchuan leachate organic matter content increased in summer, the reason is that the influence of landfill leachate is complex, such as landfill landfill age, operation mode, climatic characteristics, and waste components. It is worth further studying these influencing factors.
3.2. Fluorescence Emission Spectrum of Leachate DOM. DOM is a complex mixture comprised of fluorescent groups. The band wide fluorescence peak is shown in Figure 3. Fluorescence intensity maximum at about $412 \mathrm{~nm}$ is obtained, and the fluorescence is made from unsaturated hydroxyl and carbonyl in the DOM. In spring, the fluorescence intensity of landfill leachate DOM at ex $=335 \mathrm{~nm}$ shows gradually increasing trend with landfill time, which is consistent with the result of three-dimensional fluorescence spectrum. However, the fluorescence intensity of Jiangjin leachate DOM in at $\mathrm{ex}=335 \mathrm{~nm}$ is strong on the contrary. The reasons may be many, which is worthy of further exploration.

The fluorescence index $f_{450 / 500}$ can describe the humic acid in the water. The index $f_{450 / 500}=1.4$ indicates that the humic acid generated from land, $f_{450 / 500}=1.9$, indicates that the humic acid produced by organisms [20]. The index $f_{450 / 500}$ of Jiangjin, Yongchuan, and Dazu spring leachate is $3.0,2.9$, and 2.8 , respectively. The index $f_{450 / 500}$ of summer Yongchuan is 2.7. The index $f_{450 / 500}$ of autumn of these three regions is $3.0,2.8$, and 2.8 , respectively. These values $(>1.9)$ indicate that humus leachate comes from organisms. The higher $f_{450 / 500}$ values reveal that humic substances aromatic is weak with less benzene ring structure. The fluorescence index increased with the decrease of landfill time. As the landfill time becomes longer, the contribution of microorganism to fluorescence increased.

3.3. Infrared Spectra of Landfill Leachate DOM. FTIR can provide more detailed organic matter information about chemical and functional group. Various kinds of compound functional group and characteristic frequency area are located in the area of $4000 \sim 1300 \mathrm{~cm}^{-1}$. Vibration frequency is higher in this area, due to influence by the rest of small molecule. But different groups can form the interference, affecting the group's judgment. And $1300 \sim 400 \mathrm{~cm}^{-1}$ area is fingerprint region, in which a variety of functional groups do not have distinct characteristics, and it is strongly influenced by the molecular structure. Small changes of molecular structure can cause the obvious spectrum change in fingerprint region. In this study, organic constituent is relatively complex, and characteristics area is mainly used to identify the main functional groups. Each component landfill leachate infrared spectrum was shown in Figure 4, while the infrared spectrum of Yongchuan spring, summer, and autumn landfill DOM was shown Figure 5. 

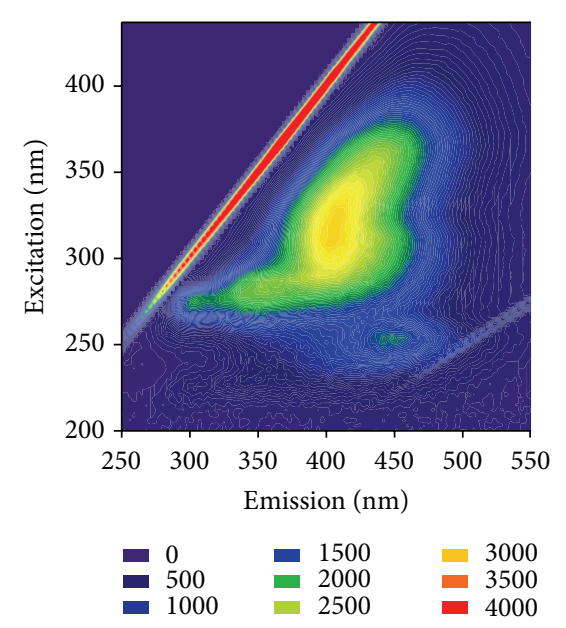

(a)

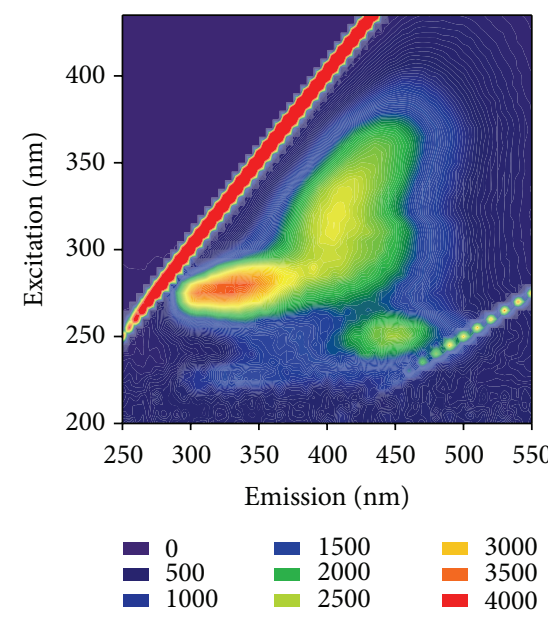

(d)
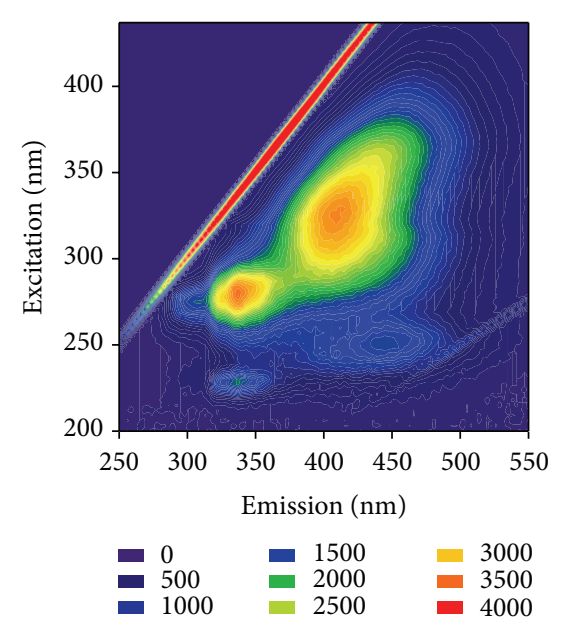

(b)
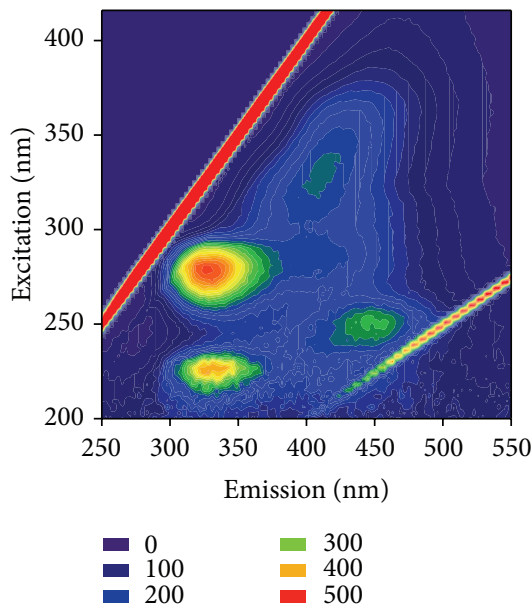

(e)

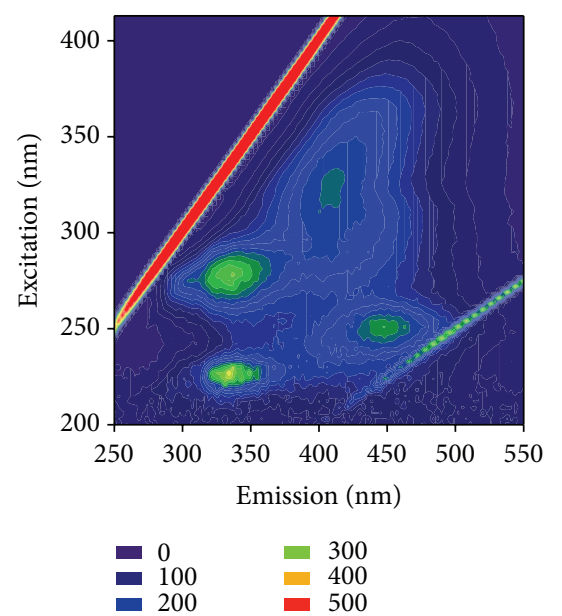

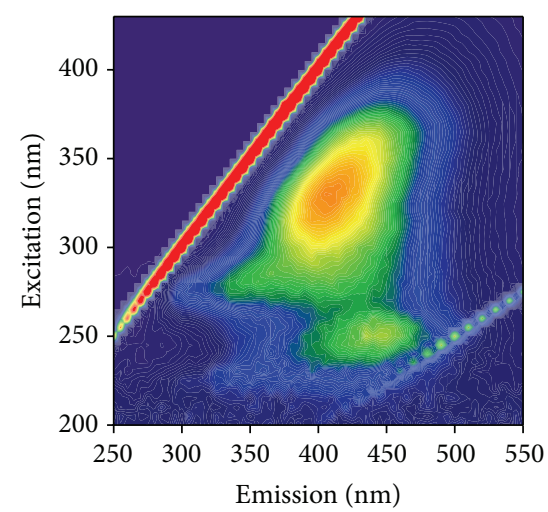

$$
\begin{array}{lll}
0 & -1500 & 3000 \\
500 & 2000 & \\
- & & 3500
\end{array}
$$

(c)

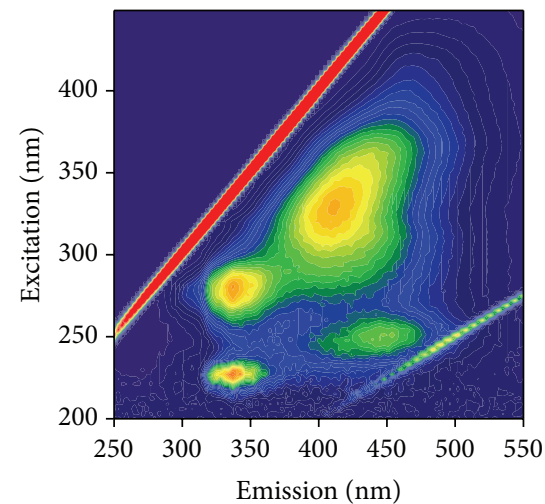

$$
\begin{array}{ll}
0 & 300 \\
-100 & 400 \\
200 & 500
\end{array}
$$

(f)

(g)

FIgURE 2: Three-dimensional fluorescence spectrum of organic matter in different landfill leachate. Note. Spring-(a) Yongchuan; (b) Jiangjin; (c) Dazu. Summer-(d) Yongchuan. Autumn-(e) Yongchuan; (f) Jiangjin; (g) Dazu (all 10 times diluted). 


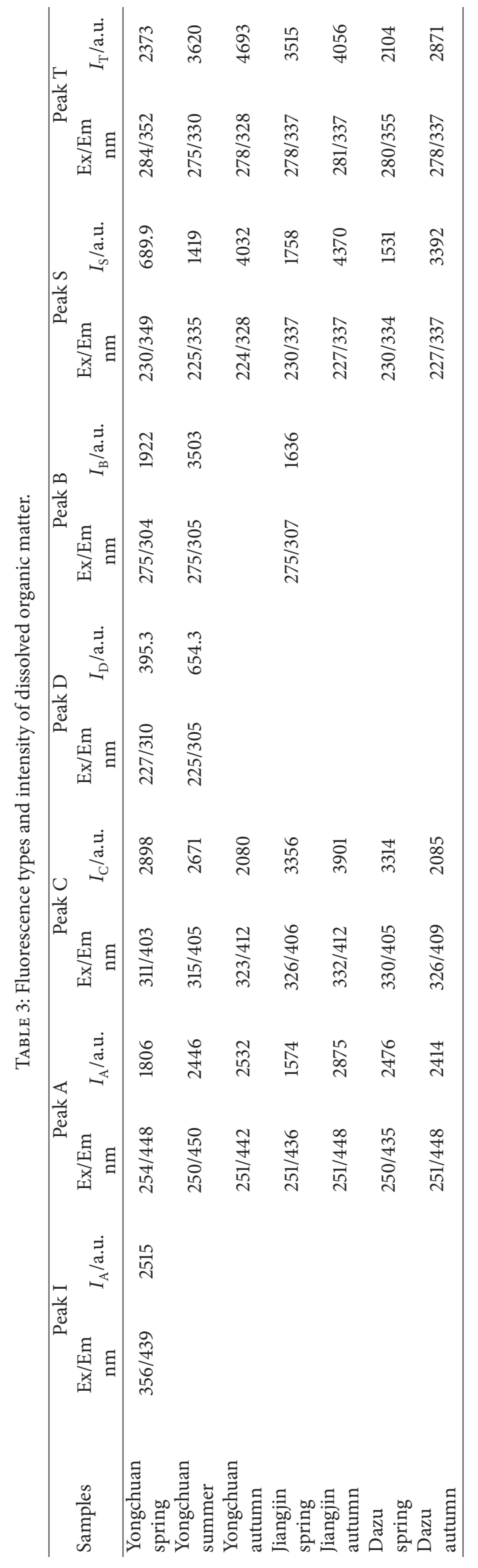




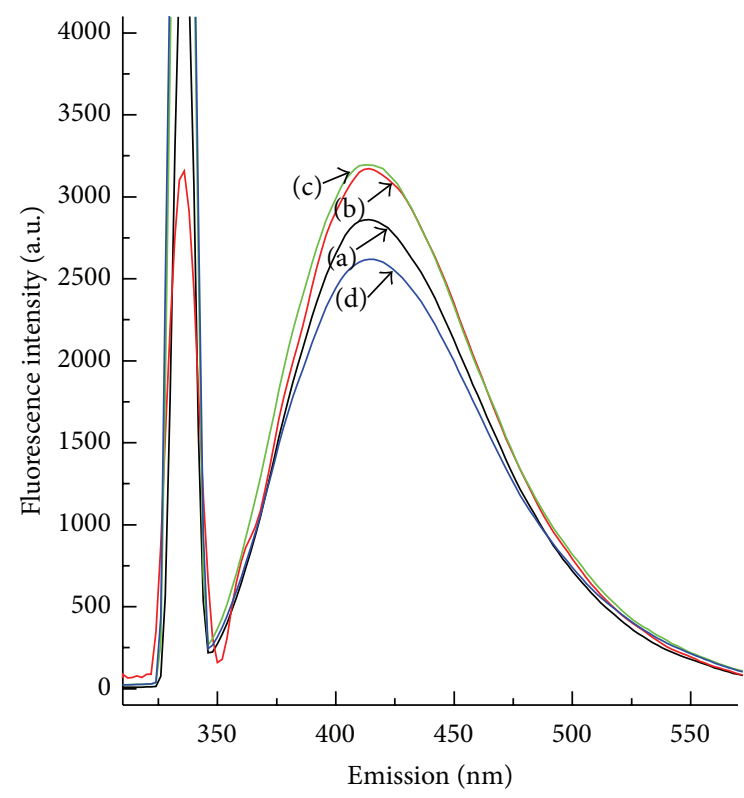

(a)

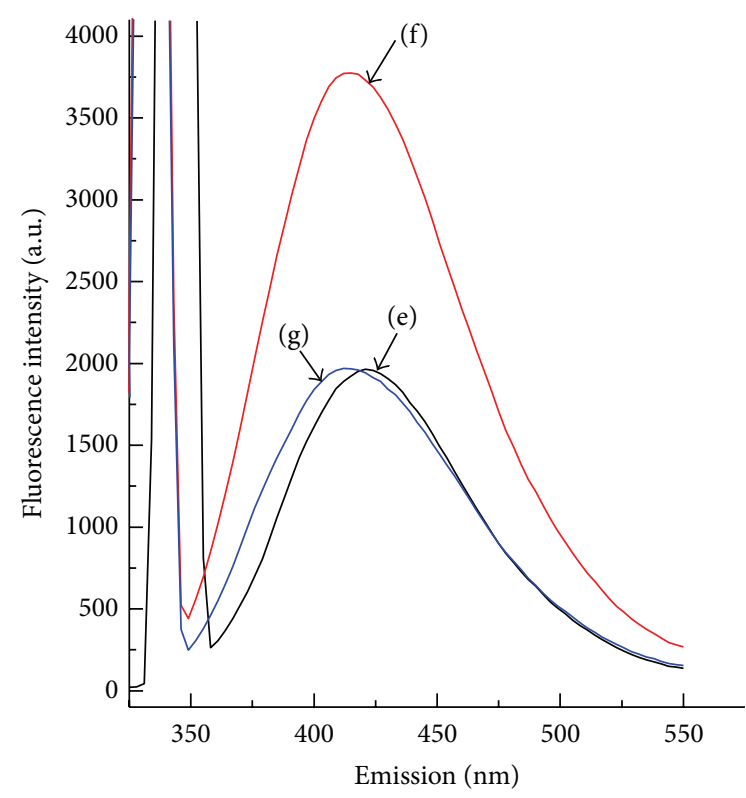

(b)

Figure 3: Fluorescence emission spectrum of DOM $(\mathrm{Ex}=335 \mathrm{~nm})$. Spring: Yongchuan (a), Jiangjin (b), and Dazu (c). Summer: Yongchuan (d). Autumn: Yongchuan (e), Jiangjin (f), and Dazu (g).

Related infrared absorption peak of humic organic matter [27-29] shows that the absorption peak in $1735 \sim 1690 \mathrm{~cm}^{-1}$ is stretching vibration of carboxyl $(\mathrm{COOH})$ group and the $\mathrm{C}=\mathrm{O}$ of ketone compounds in organic matter. The absorption peak in $1550 \sim 1515 \mathrm{~cm}^{-1}$ is deformation vibration of $\mathrm{N}-\mathrm{H}$ in nitrogen compounds, namely, the characteristic band II of amide compounds. The absorption peak in $1460 \sim 1450 \mathrm{~cm}^{-1}$ is shear type asymmetric deformation of carbohydrates and aliphatic compounds $-\mathrm{CH}_{2}$ group and asymmetric deformation vibration of $\mathrm{C}-\mathrm{H}$ in aliphatic compounds $-\mathrm{CH}_{3}$ groups. The absorption peak in $1430 \sim 1420 \mathrm{~cm}^{-1}$ is deformation vibration of aliphatic compounds in the double bond or $-\mathrm{CH}_{2}$ connected with carbonyl.

As described in Figure 4, in different seasons and the same landfill, HA and FA have similar spectrum characteristics, showing that the same source humus is more similar in functional groups and molecular structure. Different landfill site spectrum feature has greater difference, showing that different sources of humus in have great difference in functional groups and in molecular structure, and HyI spectrum has little difference.

IR analysis showed that the components of different molecular weight in terms of functional group and the molecular structure are relatively similar, but the same molecular weight of each components spectrum feature has greater differences, whereas the composition of different landfills is similar. All ingredients in $1637 \sim 1644 \mathrm{~cm}^{-1}$ area have a strong stretching vibration of $\mathrm{C}=\mathrm{C}$ in aromatic ring skeleton, and the absorption intensity of HA and FA in this area is stronger than HyI and that of FA is larger than that of HA. It shows that HA and FA contain more aromatic ring structure. The absorption degree of HA and FA composition in Dazu and
Jiangjin is greater than that in Yongchuan. It shows that both Dazu and Jiangjin contain more aromatic ring structure. FA contains more aromatic ring structure than $\mathrm{HA}$, and it is higher in autumn than in spring and in summer. In all regions, HA and FA spectrum are similar, and both in 1562 $1572 \mathrm{~cm}^{-1}$ area have a strong and apparent absorption peak. This should be deformation vibration of $\mathrm{N}-\mathrm{H}$ in secondary amide. In addition, in the $1402 \mathrm{~cm}^{-1}$ area $\mathrm{HyI}$ also has a strong absorption peak, which is shear type asymmetric deformation of carbohydrates and aliphatic compounds $-\mathrm{CH}_{2}$ group and contraction vibration of $\mathrm{N}-\mathrm{H}$ in amide compounds. HyI in $1630 \mathrm{~cm}^{-1}$ area has strong absorption. HyI composition absorption intensity in Dazu is greater than the other two. In the organic matter, the concentration of $\mathrm{N}$ elements is very high; it should be shear type vibration absorption peak of a $-\mathrm{NH}_{2}$ in primary amide, and this is amide characteristic peak II. In different places, HyI components in leachate at $1400 \sim 1420 \mathrm{~cm}^{-1}$ area all have very strong absorption peak; this is because the $\mathrm{C}=\mathrm{O}$ stretching vibration absorption.

According to Figure 5, the spectroscopic characteristic of FA and HyI in same landfill with different season is similar, except for the absorption peak position. This result indicated that the functional group and molecular structure of same source of fulvic acid and hydrophilic organic matter are similar. The obvious difference of HA atlas indicated that the structure and composition of humic acid affect the degradation of humus.

\section{Conclusions}

From the three-dimensional fluorescence spectrum analysis of garbage leachate, it is concluded that the characteristic 


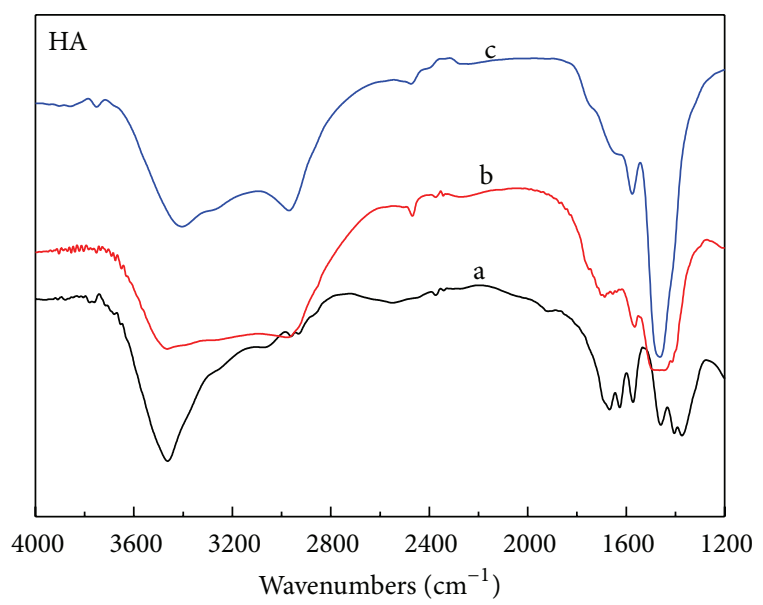

(a)

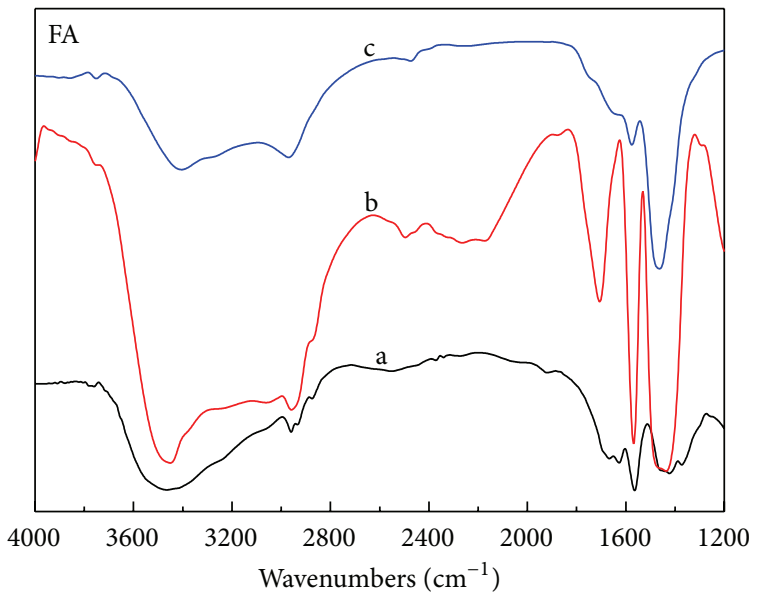

(b)

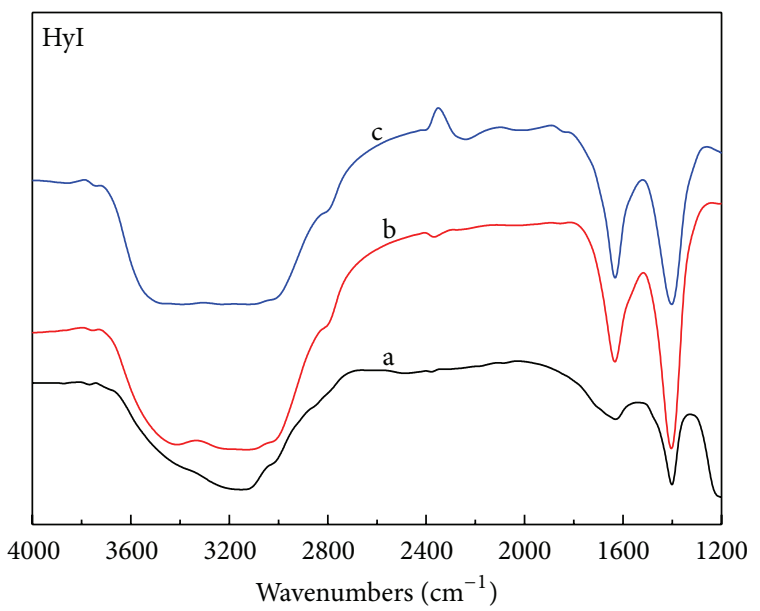

(c)

Figure 4: HA, FA, and HyI FTIR spectra from different landfill site. Notes: a-Yongchuan, b-Jiangjin, and c-Dazu.

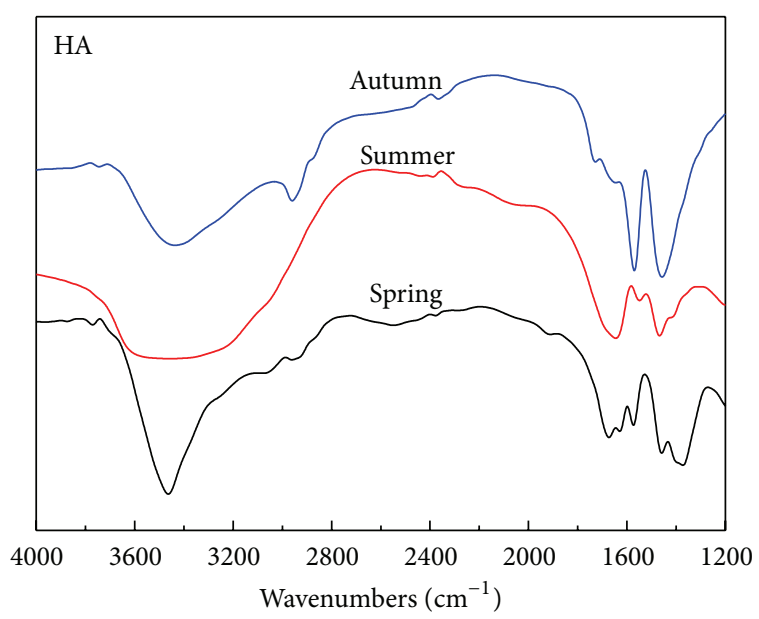

(a)

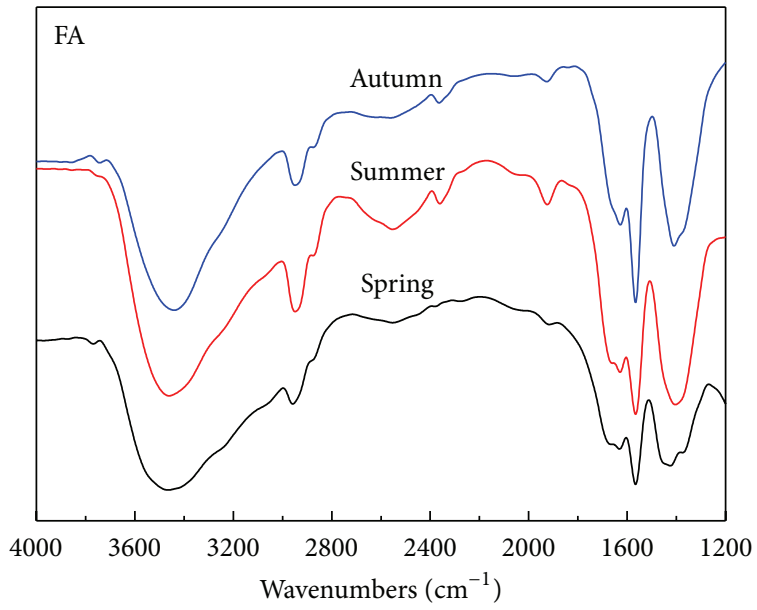

(b)

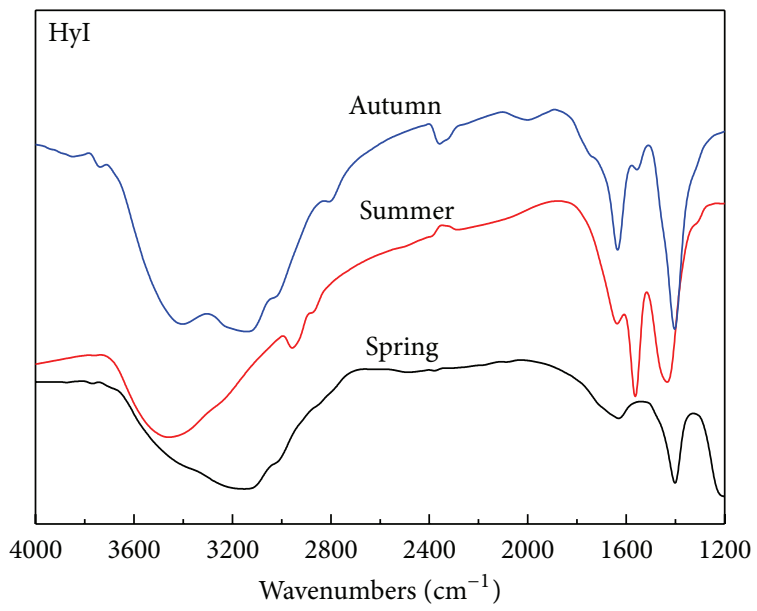

(c)

FIGURE 5: HA, FA, and HyI FTIR spectra in different season site (Yongchuan). 
peak type, position, and fluorescence intensity of landfill leachate organic matter in different landfill leachate are different season and different region. In different landfill, leachate DOM structure is different that is mainly embodied in leachate. HA proportion in Yongchuan is greater than that in other regions, and FA and HyI regional difference is not large.

Three-dimensional fluorescence spectra of the landfill leachate varied with rubbish stacking time. The longer the waste stacking time, the lower the protein in leachate concentration, and the higher the fulvic-like acid concentration. It shows that the protein material in the garbage is easily degraded in the process of humification, and it humified and produced all sorts of humus. These have some guiding significance in landfill leachate treatment.

Infrared spectrum analysis shows that, in the same area among different components, they have similar spectrum characteristics. It indicates that the same source humus in terms of functional group and molecular structure is relatively similar. Characteristic frequency area analysis shows that FA contains more aromatic ring structure than HA. In autumn there is more aromatic ring structure. Due to deformation vibration of $\mathrm{N}-\mathrm{H}$ in secondary amide, all the components in $1562 \sim 1572 \mathrm{~cm}^{-1}$ area has a very intense and obvious absorption peak. HyI contains a lot of nitrogen compounds and fatty acid organic matter.

\section{Conflict of Interests}

The authors declare that there is no conflict of interests regarding the publication of this paper.

\section{Acknowledgments}

The present work was financially supported by Scientific Research Fund, Chongqing Municipal Education Commission (no. KJ111203), and Construction Science and Technology Project of Chongqing (2011-2-115).

\section{References}

[1] B. Ozkaya, "Chlorophenols in leachates originating from different landfills and aerobic composting plants," Journal of Hazardous Materials, vol. 124, no. 1-3, pp. 107-112, 2005.

[2] P. J. He, L. M. Shao, X. Qu, G. J. Li, and D. J. Lee, "Effects of feed solutions on refuse hydrolysis and landfill leachate characteristics," Chemosphere, vol. 59, no. 6, pp. 837-844, 2005.

[3] T. Fukushima, T. Ishibashi, and A. Imai, "Chemical characterization of dissolved organic matter in Hiroshima Bay, Japan," Estuarine, Coastal and Shelf Science, vol. 53, no. 1, pp. 51-62, 2001.

[4] K. Michel, E. Matzner, M. F. Dignac, and I. Kögel-Knabner, "Properties of dissolved organic matter related to soil organic matter quality and nitrogen additions in Norway spruce forest floors," Geoderma, vol. 130, no. 3-4, pp. 250-264, 2006.

[5] S. Amir, M. Hafidi, G. Merlina, and J.-C. Revel, "Structural characterization of fulvic acids during composting of sewage sludge," Process Biochemistry, vol. 40, no. 5, pp. 1693-1700, 2005.
[6] A. Brown, D. M. McKnight, Y. P. Chin, E. C. Roberts, and M. Uhle, "Chemical characterization of dissolved organic material in Pony Lake, a saline coastal pond in Antarctica," Marine Chemistry, vol. 89, no. 1-4, pp. 327-337, 2004.

[7] K. Hautala, J. Peuravuori, and K. Pihlaja, "Measurement of aquatic humus content by spectroscopic analyses," Water Research, vol. 34, no. 1, pp. 246-258, 2000.

[8] A. Baker and M. Curry, "Fluorescence of leachates from three contrasting landfills," Water Research, vol. 38, no. 10, pp. 26052613, 2004.

[9] H. J. Fan, H. Y. Shu, H. S. Yang, and W. C. Chen, "Characteristics of landfill leachates in central Taiwan," Science of the Total Environment, vol. 361, no. 1-3, pp. 25-37, 2006.

[10] H. Youssef, D. Ibrahim, S. Komarneni, and K. J. D. Mackenzie, "Synthesis of $11 \AA$ Al-substituted tobermorite from trachyte rock by hydrothermal treatment," Ceramics International, vol. 36, no. 1, pp. 203-209, 2010.

[11] M. A. Nanny and N. Ratasuk, "Characterization and comparison of hydrophobic neutral and hydrophobic acid dissolved organic carbon isolated from three municipal landfill leachates," Water Research, vol. 36, no. 6, pp. 1572-1584, 2002.

[12] L. Persson, T. Alsberg, A. Ledin, and G. Odham, "Transformations of dissolved organic matter in a landfill leachate-a size exclusion chromatography/mass spectrometric approach," Chemosphere, vol. 64, no. 7, pp. 1093-1099, 2006.

[13] Y.-D. Xu, D.-B. Yue, Y. Zhu, and Y.-F. Nie, "Fractionation of dissolved organic matter in mature landfill leachate and its recycling by ultrafiltration and evaporation combined processes," Chemosphere, vol. 64, no. 6, pp. 903-911, 2006.

[14] J. Rodriguez, L. Castrillon, E. Maranon, H. Sastre, and E. Fernandez, "Removal of non-biodegradable organic matter from landfill leachates by adsorption," Water Research, vol. 38, no. 14-15, pp. 3297-3303, 2004.

[15] E. M. Thurman and R. L. Malcolm, "Preparative isolation of aquatic humic substances," Environmental Science and Technology, vol. 15, no. 4, pp. 463-566, 1981.

[16] J. B. Christensen, D. L. Jensen, C. Gron, Z. Filip, and T. H. Christensen, "Characterization of the dissolved organic carbon in landfill leachate-polluted groundwater," Water Research, vol. 32, no. 1, pp. 125-135, 1998.

[17] S. Petzet, B. Peplinski, and P. Cornel, "On wet chemical phosphorus recovery from sewage sludge ash by acidic or alkaline leaching and an optimized combination of both," Water Research, vol. 46, no. 12, pp. 3769-3780, 2012.

[18] P. G. Coble, "Characterization of marine and terrestrial DOM in seawater using excitation-emission matrix spectroscopy," Marine Chemistry, vol. 51, no. 4, pp. 325-346, 1996.

[19] D. M. McKnight, E. W. Boyer, P. K. Westerhoff, P. T. Doran, T. Kulbe, and D. T. Andersen, "Spectrofluorometric characterization of dissolved organic matter for indication of precursor organic material and aromaticity," Limnology and Oceanography, vol. 46, no. 1, pp. 38-48, 2001.

[20] F. Wu, T. Midorikawa, and E. Tanoue, "Fluorescence properties of organic ligands for copper(II) in Lake Biwa and its rivers," Geochemical Journal, vol. 35, no. 5, pp. 333-346, 2001.

[21] F. Wu and E. Tanoue, "Isolation and partial characterization of dissolved copper-complexing ligands in streamwaters," Environmental Science and Technology, vol. 35, no. 18, pp. 3646-3652, 2001.

[22] F. C. Wu, R. D. Evans, and P. J. Dillon, "Separation and characterization of NOM by high-performance liquid chromatography and on-line three-dimensional excitation emission matrix 
fluorescence detection," Environmental Science and Technology, vol. 37, no. 16, pp. 3687-3693, 2003.

[23] F. C. Wu, E. Tanoue, and C. Q. Liu, "Fluorescence and amino acid characteristics of molecular size fractions of DOM in the waters of Lake Biwa," Biogeochemistry, vol. 65, no. 2, pp. 245257, 2003.

[24] L. Ziyang and Z. Youcai, "Size-fractionation and characterization of refuse landfill leachate by sequential filtration using membranes with varied porosity," Journal of Hazardous Materials, vol. 147, no. 1-2, pp. 257-264, 2007.

[25] Z.-L. Ye, S.-H. Chen, S.-M. Wang et al., "Phosphorus recovery from synthetic swine wastewater by chemical precipitation using response surface methodology," Journal of Hazardous Materials, vol. 176, no. 1-3, pp. 1083-1088, 2010.

[26] K.-H. Kang, H. S. Shin, and H. Park, "Characterization of humic substances present in landfill leachates with different landfill ages and its implications," Water Research, vol. 36, no. 16, pp. 4023-4032, 2002.

[27] S. Kuwatsuka, A. Watanabe, K. Itoh, and S. Arai, "Comparison of two methods of preparation of humic and fulvic acids, IHSS method and NAGOYA method," Soil Science and Plant Nutrition, vol. 38, no. 1, pp. 23-30, 1992.

[28] Y. Inbar, Y. Chen, and Y. Hadar, "Carbon12 13CPMAS NMR and FTIR spectroscopic analysis of organic matter transformations during decomposition of solid wastes from wineries," Soil Science, vol. 4, pp. 272-281, 1991.

[29] D. T. Durig, J. S. Esterle, T. J. Dickson, and J. R. Durig, "Investigation of the chemical variability of woody peat by FTIR spectroscopy," Applied Spectroscopy, vol. 42, no. 7, pp. 1239$1244,1988$. 

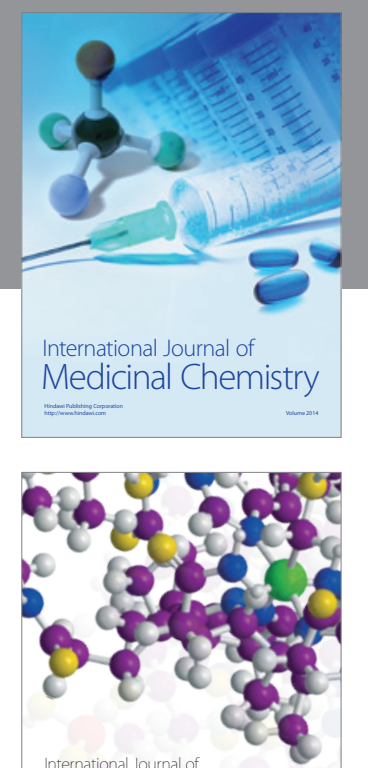

\section{Carbohydrate} Chemistry

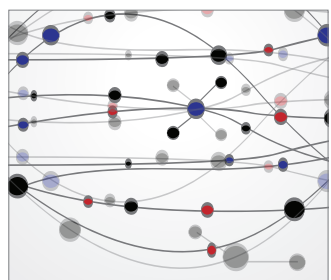

The Scientific World Journal
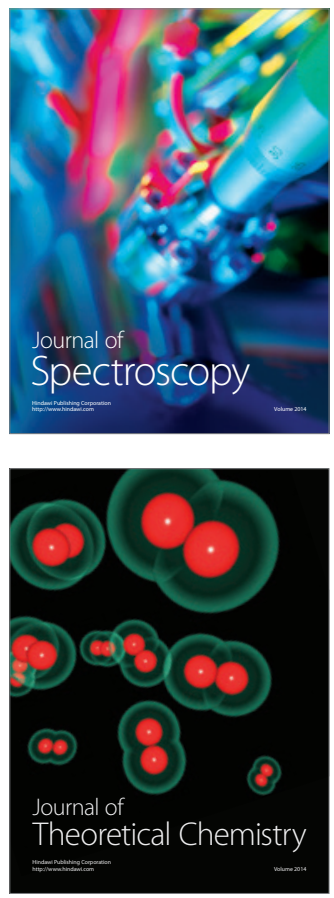
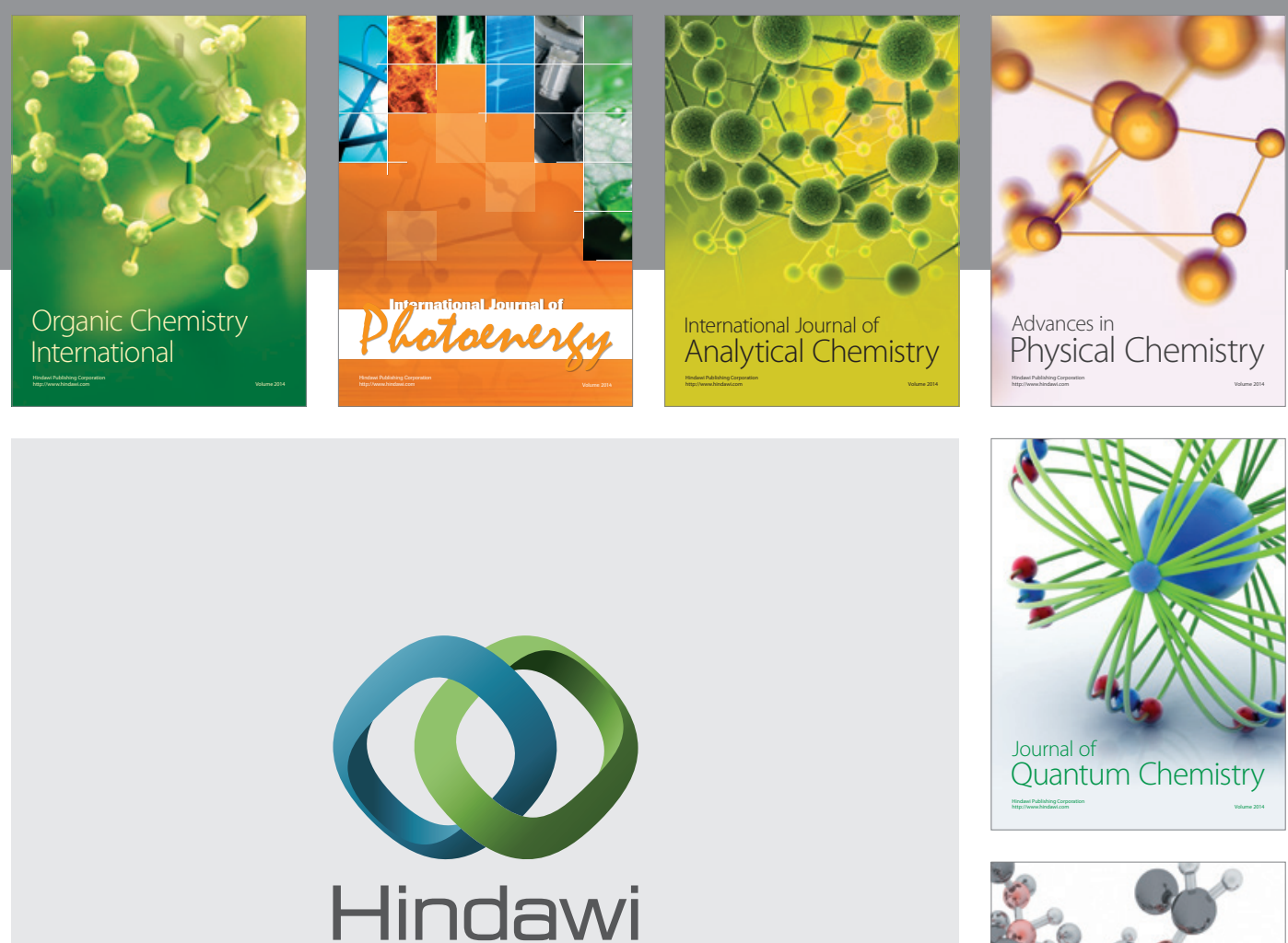

Submit your manuscripts at

http://www.hindawi.com

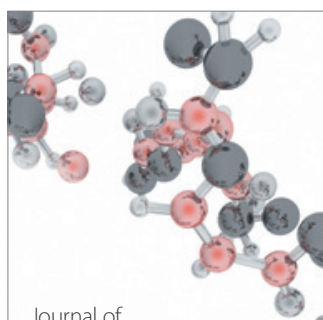

Analytical Methods

in Chemistry

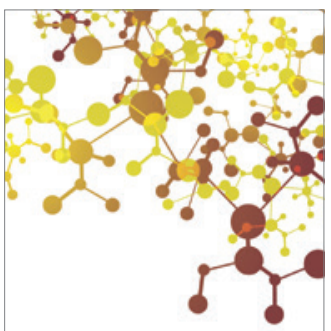

Journal of

Applied Chemistry

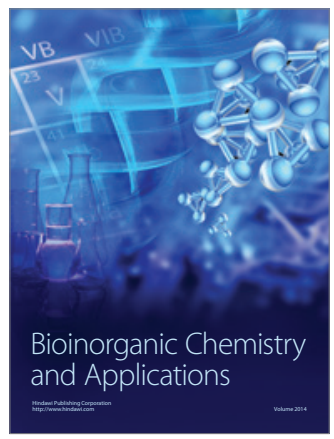

Inorganic Chemistry
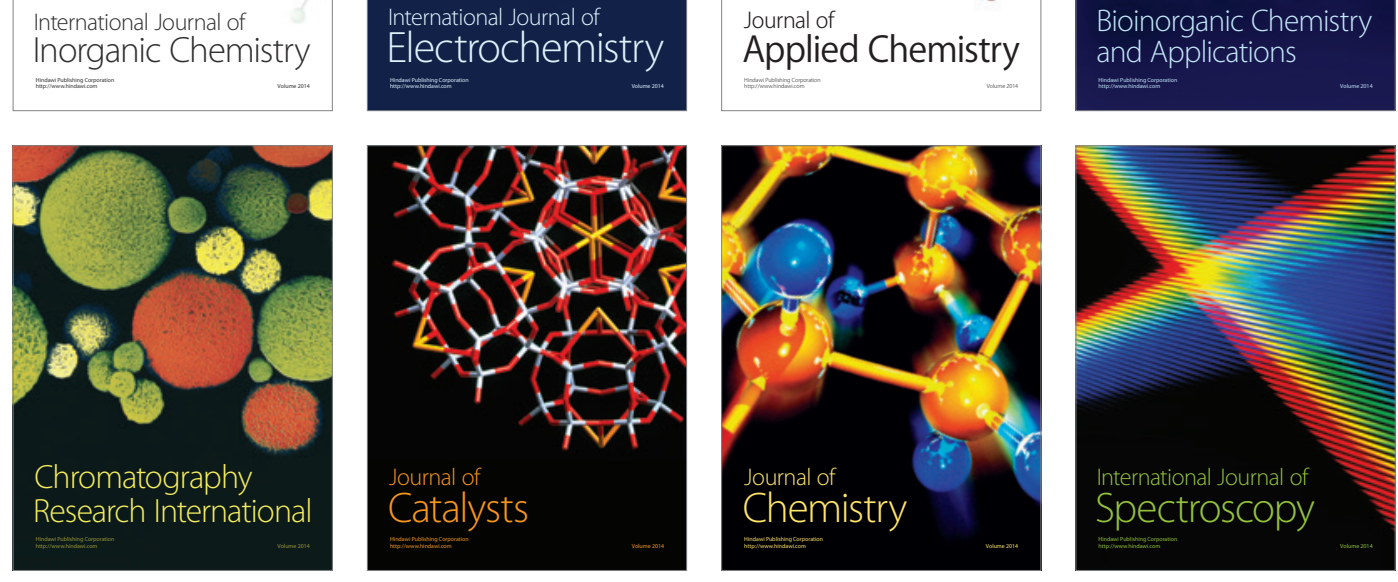